\title{
Sustainability rating tools for buildings and its wider application
}

\author{
Renard Siew \\ University of New South Wales, Australia
}

Received: 6 April 2016 / Accepted: 26 November 2016

\begin{abstract}
This paper provides a commentary on the latest research in measuring the sustainability of buildings and its wider application. The emergence of sustainability rating tools (SRTs) has faced critique from scholars due to their deficiencies such as the overemphasis on environmental criteria, the negligence of uncertainty in scoring and existence of non-scientific criteria benchmarks among many others. This could have attributed to the mixed evidence in the literature on the benefits of SRTs. Future research direction is proposed to advance the state-of-the art in this field.
\end{abstract}

Keywords: sustainability rating tools (SRTs) / sustainability / buildings / limitations / green buildings

Sustainable development has been internationally agreed as a key goal for policy makers to guide development at global, national and local levels [1]. The World Economic Forum [2] identifies the building sector as an area which needs to be addressed because it accounts for " $40 \%$ of the world's energy use, $40 \%$ of carbon output and consumes $20 \%$ of available water". The increased recognition that buildings is a major contributor towards climate change puts pressure on construction practitioners to not just focus on traditional project goals of cost and time. Against this background, a number of rating tools have surfaced in the market to help articulate the extent by which construction activities are sustainable. While this move is welcomed with good intentions, it has also created much confusion among stakeholders. One of my research focus is on measuring the effectiveness of these rating tools in relation to buildings/infrastructure [3-5]. On the surface, there are clearly deficiencies with these tools which will need to be addressed before "claims" can be made that our industry is advancing the sustainability agenda. Some of these notable deficiencies include among others: the overemphasis on environmental issues with little consideration for social or governance issues; scoring which does not account for uncertainty or variability in assessors' perceptions; lack of published reasoning behind allocation of scores; inadequate definition of scales to permit differentiation among projects; and the existence of nonscientific benchmarks [3].

In terms of application, these tools are also used as the de-facto standard for rating the "greenness" of portfolios. An extension of my research examines how the capital markets value or respond to "green" real estate investment

\footnotetext{
* e-mail: rensiew10@gmail.com
}

trusts (REITs) [6,7]. The study of real estate investment trusts (REITs) has been a subject of much interest especially among investors. Some scholars find that returns from REITs mirrored that of the equities market with no strong evidence of co-movement with direct real estates. Others claim that REITs are able to replicate the performance of direct real estates and are therefore suitable candidates for diversification in investment portfolios. Given the growing movement of the socially responsible investment (SRI) market which stresses on the need to integrate "green" criteria into investment decision making, it would be interesting to explore whether the "green premium" does exist for REITs. This is important as an overwhelming number of studies are currently focused on equities and the evidence base on the benefits of investing in "green" REITs is scarce.

I further tested the behaviour of "green" REITs by using samples from the Australian market. The findings showed that price movement among "green" REITs is nonhomogeneous. This means that the price movement of "green" REITs cannot be generalised and instead each REIT must be analysed individually to derive any significant conclusions about price movement. These findings confirm to both analyst and institutional investors that investing in REITs is potentially a viable option for portfolio diversification as they are not necessarily affected by trend movements. As well, the effect of heterogeneity in the price movement of REITs may be amplified as information concerning different property companies becomes available at various times. The "short-termism" approach of investors could also exacerbate the situation. That is to say that investors are expected to react momentarily (buy or sell REITs) due to the effects of information asymmetry (exposure to company news is 
different among investors at different points in time). In turn, this contributes to the non-homogeneous behaviour among REITs.

No evidence was found, however, demonstrating the superiority of "green" REITs over "non-green" REITs. One reason advanced is that there may be different interpretations of "green" performance among investors. This could be attributed to the range of terminology and standards used to assess "green" performance relating to the construction and real estate industry. The term "sustainable construction" is poorly defined in many aspects of the literature, often with ambiguous words, leading to much confusion, large inconsistencies and multiple interpretations. Discourse associated with sustainable development becomes challenging with the involvement of parties with varying backgrounds working in the real estate industry. There is ongoing debate about what is to be sustained, at what scale (boundary conditions) and how this is to be done. Due to the lack of agreed definition, there is difficulty in providing guidance for best practices based on well accepted and understood concepts and ideas. Once again this is reflective of the afore-mentioned deficiencies of "green" rating tools for buildings.

Research has a significant role to play in challenging and shaping the landscape of sustainable buildings. I wish to highlight several potential leads for future research which would be useful to those working in this space:

- Harmonisation of SRTs: There is still much confusion about what constitutes truly sustainable buildings and part of this reason is due to the increasing number of SRTs in the market differentiated by geographical location. Much work needs to be done to streamline and ensure there is alignment of definition and terminology.
- Benefits of SRTs: While there have been many speculative benefits of SRTs, the evidence base is mixed. There needs to be more empirical research conducted to ascertain the true value of SRTs. The scope should not just cease at examining the operational performance of buildings rated with SRTs but also to look at whether these SRTS have an impact in the capital markets.

- Scientific baselines: One of the major criticisms of current SRTs is that there is no real scientific evidence for the baselines set across a range of criteria. Researchers should challenge the validity of these baselines on whether they were developed based on "gut-feel" or through a rigorously tested method.

\section{References}

1. R.K. Singh, H.R. Murty, S.K. Gupta, A.K. Dikshit, An overview of sustainability assessment methodologies, Ecol. Indic. 9 (2), 189-212 (2009)

2. World Economic Forum, A profitable and resource efficient future: catalysing retrofit finance and investing in commercial real estate (World Economic Forum, Geneva, 2011)

3. R.Y.J. Siew, M.C.A. Balatbat, D.G. Carmichael, A review of building/infrastructure sustainability reporting tools (SRTs), Smart Sustain. Built. Environ. 2 (2), 106-139 (2013)

4. R.Y.J. Siew, Evaluating and enhancing the impact of sustainability reporting tools (SRTs), Ph.D. thesis, School of Civil and Environmental Engineering, University of New South Wales, Sydney, 2014

5. R.Y.J. Siew, A review of sustainability reporting tools (SRTs) for communities, Int. J. Sustain. Constr. Eng. Technol. 5 (2), 39-52 (2014)

6. R.Y.J. Siew, A review of corporate sustainability reporting tools (SRTs), J. Environ. Manag. 164, 180-195 (2015)

7. R.Y.J. Siew, Predicting the behaviour of Australian ESG REITs using Markov Chain analysis, J. Financ. Manag. Prop. Constr. 20 (3), 252-267 (2015)

Cite this article as: R. Siew: Sustainability rating tools for buildings and its wider application. Sust. Build. 2, 2 (2017). 